\title{
Análise de crescimento e partição de fotoassimilados em plantas de abóbora híbrida Tetsukabuto submetidas a doses de nitrogênio
}

\section{Growth analysis and photoassimilates partition in Tetsukabuto hybrid squash plants submitted to nitrogen doses}

\section{Sanzio Mollica VIDIGAL ${ }^{1}$; Mário PUIATTI²; Maria Aparecida Nogueira SEDIYAMA ${ }^{3}$}

${ }^{1}$ Autor para correspondência, Engenheiro agrônomo, Pesquisador, Epamig Sudeste, Empresa de Pesquisa Agropecuária de Minas Gerais, Vila Gianetti, 46/47, Campus da UFV, 36570-075, Viçosa, Minas Gerais, Brasil. (31) 3891-2646. sanziomv@epamig.br.

${ }^{2}$ Engenheiro agrônomo, Professor Titular, Departamento de Fitotecnia, Universidade Federal de Viçosa, Viçosa, Minas Gerais, Brasil.mpuiatti@ufv.br

${ }^{3}$ Engenheira agrônoma, Pesquisadora, Epamig Sudeste, Empresa de Pesquisa Agropecuária de Minas Gerais, Viçosa, Minas Gerais, Brazil.mariasediyama@gmail.com

Recebido em: 25-09-2020; Aceito em: 15-12-2020

\section{Resumo}

O nitrogênio (N) é o segundo nutriente mais absorvido pela abóbora Tetsukabuto, mas não se conhece a influência de doses de $\mathrm{N}$ nas fases de crescimento e na partição de fotoassimilados na planta, sendo este o objetivo deste estudo. Para tanto, avaliaram-se cinco doses de N (0,30,60, 120 e $\left.240 \mathrm{~kg} \mathrm{ha}^{-1}\right)$, em cobertura. O delineamento foi em blocos ao acaso, com quatro repetições. A partir de 30 dias após a semeadura, as plantas foram coletadas a intervalos regulares de 15 dias ao longo do ciclo de cultivo, sendo determinados a massa seca. A partir dos dados primários, foi aplicada a análise de crescimento, sendo calculados a massa seca total da planta (Wt), parte aérea (Wpa), fruto (Wfr) e raiz (Wr), as taxas de crescimento absoluto da planta (Cwt) e do fruto (Cwfr), a partição de massa seca entre órgãos e o número e massa fresca de frutos. A máxima produtividade de frutos (13.609 $\left.\mathrm{kg} \mathrm{ha}^{-1}\right)$, a maior Wt $\left(864,07 \mathrm{~g}_{\text {planta- }}{ }^{-1}\right)$ e a maior Cw $\left(36,87 \mathrm{~g} \mathrm{planta}^{-1} \mathrm{dia}^{-1}\right)$ foram estimadas com $149 \mathrm{~kg} \mathrm{ha}^{-1} \mathrm{de} \mathrm{N}$. Os frutos acumularam de 54,5 a $76,2 \%$ da Wt. O nitrogênio altera o crescimento e a partição de fotoassimilados entre os órgãos da planta.

Palavras-chave adicionais: adubação nitrogenada; Cucurbita maxima x Cucurbita moschata; massa seca; produtividade.

\begin{abstract}
Nitrogen is the second most absorbed nutrient by the tetsukabuto squash, but the influence of $\mathrm{N}$ on the growth phases and photoassimilated partition in plants is unknown. Therefore, it is proposed to evaluate the influence of nitrogen on growth, photoassimilated partition and tetsukabuto hybrid squash yield. The rates of $\mathrm{N}(0 ; 30 ; 60 ; 120$ and $240 \mathrm{~kg} \mathrm{ha}^{-1}$ ), applied in cover were evaluated. The design was in random blocks, with four replicates. From 30 days after sowing, the plants were collected at regular intervals of 15 days along the cultivation cycle and the dry mass was determined. From the primary data, the growth analysis was applied and the total dry mass of the plant $(\mathrm{Wt})$, aerial part (Wpa), fruit (Wfr) and root (Wr), the absolute growth rates of the plant (Cwt) and fruit (Cwrr), the dry mass partition between organs and the number and fresh mass of fruits were calculated. The maximum fruit yield $\left(13,609 \mathrm{~kg} \mathrm{ha}^{-1}\right)$, the highest Wt (864.07 $\left.\mathrm{g} \mathrm{plant}^{-1}\right)$ and the highest Cw (36.87 $\mathrm{g} \mathrm{plant}^{-1}$ day $\left.^{-1}\right)$ were estimated with $149 \mathrm{~kg}$ ha- 1 of $\mathrm{N}$. The fruit accumulated from 54.5 to $76.2 \%$ of Wt. The plants had four growth phases and the duration of the phases varied with the doses of $\mathrm{N}$ : Phase I - slow accumulation up to $10 \%$ of Wt (42 to 48 days); Phase II - accelerated accumulation up to $50 \%$ of Wt and maximum Cw (10 to 14 days); Phase III - slowed accumulation up to $100 \%$ of Wt, associated with fruit ripening (19 to 28 days) and Phase IV - reduction of Wt and negative values of $\mathrm{Cw}$ until fruit harvest ( 3 to 19 days). Nitrogen alters the growth and partition of photoassimilates between the plant organs.
\end{abstract}

Additional keywords: Cucurbita maxima x Cucurbita moschata; dry matter; nitrogen fertilization; yield.

\section{Introdução}

Para as hortaliças, em geral, os estudos de crescimento de plantas é caracterizado e descrito por fases de desenvolvimento em função de modelos matemáticos do tipo sigmoidal ou exponencial, que demonstra de três a quatro fases de crescimento: a primeira fase, as plantas têm crescimento lento no início, ou seja, desde a semeadura ou após o transplantio de mudas; a segunda fase, o crescimento é rápido e uma terceira fase, seguida ou não de uma quarta fase, na qual há uma tendência de estabilização no crescimento e na quarta fase, observa-se uma queda no crescimento, dependendo do ciclo da espécie 
até a colheita final de seu produto comercial (Vidigal et al, 2007; Vidigal et al, 2010; Almeida et al, 2012; Pedó et al, 2013; Kutz et al, 2016; Cecílio Filho et al, 2017).

O nitrogênio $(\mathrm{N})$ é o segundo nutriente mais absorvido pela cultura, superado apenas pelo potássio (Vidigal et al., 2007). Promove alterações morfofisiológicas na planta, estando relacionado com a fotossíntese, o desenvolvimento e atividades das raízes, absorção iônica de nutrientes, crescimento e diferenciação celular (Marschner, 2012).

Não se conhece como a disponibilidade de $\mathrm{N}$ influencia as fases de crescimento e a partição de fotoassimilados nas plantas de abóbora híbrida Tetsukabuto (Cucurbita maxima x Cucurbita moschata). Em abóbora Tetsukabuto, a adubação nitrogenada aumenta a produção de frutos; entretanto, a produção máxima de frutos comercializáveis é variável com a cultivar/híbrido, época de cultivo, época de aplicação de N e tipo de solo (Pedrosa et al., 2012; Pôrto et al., 2014; Marouelli et al., 2017). Em meloeiro, também uma cucurbitácea, o aumento na dose de N, até certo ponto, proporcionou aumento na área foliar, com efeito na produção de fotoassimilados e, consequentemente, na produção de frutos. Assim, o $\mathrm{N}$ exerce influência no crescimento e desenvolvimento das plantas com efeito direto nas relações fonte/dreno, por alterar a distribuição de assimilados entre a parte vegetativa e reprodutiva (Queiroga et al., 2007). Entretanto, o acúmulo de massa seca nas plantas de melão não foi influenciado pelas doses de $\mathrm{N}$ e $\mathrm{K}$ aplicada na fertirrigação (Damasceno et al., 2012).

O objetivo do trabalho foi avaliar a influência do nitrogênio no crescimento, na partição de fotoassimilados e na produtividade de abóbora híbrida Tetsukabuto.

\section{Material e métodos}

O experimento foi conduzido no Campo Experimental de Mocambinho, da EPAMIG, no Município de Jaíba-MG, Norte de Minas Gerais (15,08ㅇ; 44,02W; $452 \mathrm{~m}$ ), em NEOSSOLO QUARTZARÊNICO, textura arenosa, que na análise química, na camada de 0 a $20 \mathrm{~cm}$ de profundidade, obteve as seguintes características: $\mathrm{pH}$ (água 1:2,5) = 5,8; $\mathrm{Ca}^{2+}=2,00 ; \mathrm{Mg}^{2+}=0,35$; $\mathrm{Al}^{3+}=0,00$ e $\mathrm{H}+\mathrm{Al}=0,90$, expressos em cmolc $\mathrm{dm}^{-3} \mathrm{e}$ $\mathrm{P}=50,45 \mathrm{mg} \mathrm{dm}^{-3}$ (Mehlich 1); $\mathrm{K}=38,00 \mathrm{mg} \mathrm{dm}^{-3} \mathrm{e}$ matéria orgânica $=5,20 \mathrm{~g} \mathrm{~kg}^{-1}$.

Foram avaliadas cinco doses de $\mathrm{N}(0,30,60$, 120 e $240 \mathrm{~kg} \mathrm{ha}^{-1}$ ), em cobertura, aplicado na forma de ureia, sendo $20 \%$ da dose aplicada aos 25 dias após a semeadura (DAS), $40 \%$ aos 40 DAS e $40 \%$ aos 55 DAS. A ureia foi dissolvida em água e aplicado $200 \mathrm{~mL}$ da solução por cova, sendo que na dose zero aplicouse somente água. Os tratamentos foram arranjados no delineamento experimental em blocos casualizados, com quatro repetições. A parcela experimental foi constituída de seis linhas com 12 plantas cada e a parcela útil constou de 40 plantas, obtidas nas linhas centrais.

As mudas da abóbora, híbrido B8-A (Takii) foram produzidas em bandeja de poliestireno expandido com 128 células, contendo o substrato comercial Plantmax® e o transplantio das mudas ocorreu aos 10 DAS no espaçamento de 3,0 m x 1,5 m, com uma planta por cova.

O solo foi preparado com aração e gradagem e, em seguida, as covas foram abertas. A adubação de plantio foi realizada cinco dias antes do transplantio das mudas (13 g de ureia, $250 \mathrm{~g}$ de superfosfato simples, $25 \mathrm{~g}$ de cloreto de potássio e $10 \mathrm{~g}$ de bórax). Aplicou-se também $120 \mathrm{~g}$ de cloreto de potássio por cova, em três vezes, juntamente com a adubação nitrogenada, em cobertura. No início da floração e da frutificação, aplicou-se adubo foliar CaB2 Plus na dose equivalente a 3,0 L ha-1.

A média das temperaturas máxima, mínima e média foram $34,1^{\circ} \mathrm{C} ; 19,4^{\circ} \mathrm{C}$ e $26,8^{\circ} \mathrm{C}$, respectivamente e no período de condução do experimento a precipitação pluviométrica acumulada foi de $187 \mathrm{~mm}$ (Figura 1). A irrigação foi feita por microaspersão, aplicando-se uma lâmina diária de $4,5 \mathrm{~mm}$. Os demais tratos culturais foram realizados de acordo com a necessidade e recomendação para a cultura (Nick e Borém, 2017).

Durante o período de cultivo foram retiradas amostras compostas por quatro plantas competitivas, inteiras, em cinco épocas distintas. Iniciou-se a coleta aos 30 DAS e se estendeu até aos 90 DAS considerando um intervalo regular de 15 dias. $O$ material amostrado foi separado em folha + caule (parte aérea), flor e fruto (frutos) e raiz, secado em estufa com circulação forçada de ar a $65^{\circ} \mathrm{C}$ até peso constante, para obtenção da massa seca das plantas. Esses dados foram usados para determinar a curva de acúmulo de massa seca pela abóbora híbrida.

$\mathrm{Na}$ colheita, os frutos foram classificados em três classes comerciais, de acordo com a massa fresca: fruto pequeno $(1,0$ a $1,7 \mathrm{~kg})$, fruto médio $(1,7 \mathrm{a} \mathrm{2,5} \mathrm{kg})$ e fruto grande $(>2,5 \mathrm{~kg})$. A produção comercial foi obtida pelo somatório das massas de frutos das três classes; a produção não comercial correspondeu ao somatório das massas dos frutos refugo $(<1,0 \mathrm{~kg})$ e dos frutos desqualificados devido à ocorrência de podridões, má-formação, rachaduras e danos causados pelo ataque de pragas (dados não apresentados).

Os dados foram submetidos à análise de variância e regressão. Os modelos de regressão testados foram: linear, quadrático e raiz-quadrática para variáveis de produção. Escolheu-se o modelo com base no significado biológico, na significância dos coeficientes de regressão, pelo teste $t$, e no maior coeficiente de determinação. A dose de $\mathrm{N}$ que proporcionou a máxima produtividade de frutos comerciais foi obtida igualando-se a zero a primeira derivada da equação de resposta da produção comercial de frutos às doses de N. Para a execução das análises estatísticas foi utilizado o programa Genes (Cruz, 2013). 


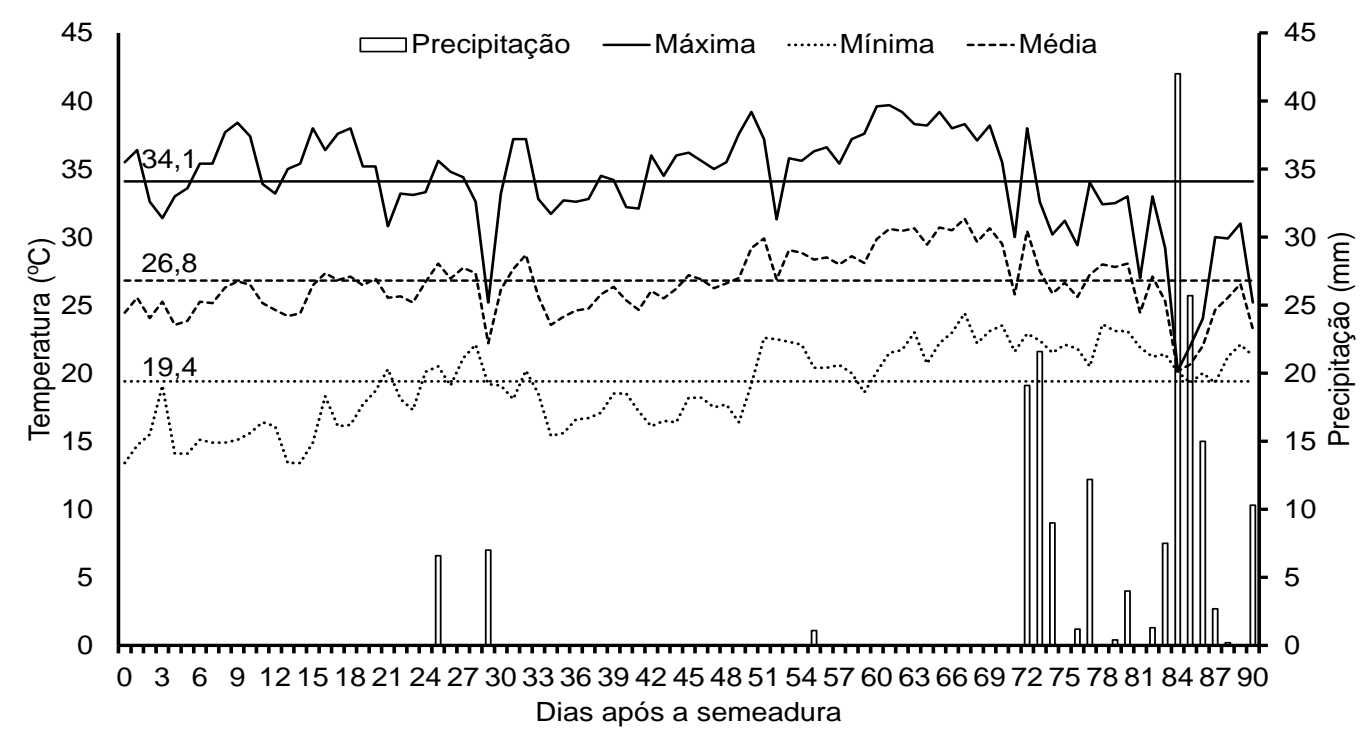

Figura 1 - Temperatura máxima, média e mínima do ar e precipitação pluviométrica diária durante o período de condução do experimento. Dados da estação meteorológica do Campo Experimental de Mocambinho da EPAMIG.

Os dados de massa seca foram submetidos à análise de regressão, tendo como variável independente as doses de N, o que permitiu estimar o crescimento das plantas, também com a dose de $\mathrm{N}$, que proporcionou a máxima produtividade de frutos comerciais.

O crescimento das plantas foi caracterizado pela produção de massa seca total da planta $(\mathrm{Wt})$, das folhas + caule (parte aérea - Wpa), flor + fruto (fruto Wfr) e raiz $(\mathrm{Wr})$. Os dados primários de massa seca acumulada (W) foram submetidos à análise de regressão, tendo como variável independente à idade da planta, expressa em dias após a semeadura, sendo ajustadas as equações $W=\exp \left(A-B x-C / x^{2}\right)$ ou $\mathrm{W}=\exp \left(\mathrm{A}-\mathrm{B} / \mathrm{x}^{2}\right)$ e a taxa de crescimento absoluto da planta (Cwt) e do fruto (Cwfr) foram estimadas por meio da derivada primeira da equação ajustada a Wt e Wfr em relação ao tempo.

\section{Resultados e discussão}

O N aumentou a produtividade de frutos comercializáveis até a dose de $149 \mathrm{~kg} \mathrm{ha}^{-1}$, alcançando a

máxima produtividade de frutos comerciais de 13.109 $\mathrm{kg} \mathrm{ha}^{-1}$ (Figura 2A). Pedrosa et al. (2012) observaram que a produtividade de frutos de abóbora Tetsukabuto foi também influenciada pelas doses de N, estimando-se como valor máximo de $11.550 \mathrm{~kg} \mathrm{ha}^{-1}$ de frutos com a dose de $300 \mathrm{~kg} \mathrm{ha}^{-1}$ de N. Pôrto et al. (2014), em solo de textura argilosa, obtiveram produtividade máxima de frutos de abóbora Tetsukabuto igual a $17.160 \mathrm{~kg} \mathrm{ha}^{-1}$ com a dose estimada de $260 \mathrm{~kg} \mathrm{ha}^{-1}$ de N. Estes autores obtiveram, ainda, as doses de máxima eficiência econômica de 251 e $238 \mathrm{~kg} \mathrm{ha}^{-1}$ de N, quando se utilizou como fonte de $\mathrm{N}$ o sulfato de amônio e o nitrato de amônio, respectivamente. Marouelli et al. (2017) observaram que a mais alta produtividade de abóbora Tetsukabuto (24.300 e $27.000 \mathrm{~kg} \mathrm{ha}^{-1}$ ) foi obtida com 105 a $146 \mathrm{~kg} \mathrm{ha}^{-1}$ de $\mathrm{N}$ e lâmina d'água de 477 a $492 \mathrm{~mm}$. Ressalta-se que os resultados acima foram obtidos com diferentes cultivares/híbridos de abóbora Tetsukabuto e solos com características distintas. Portanto, esses resultados demonstram que para a recomendação de adubação nitrogenada devese levar em consideração a produtividade almejada e as características físicas e químicas do solo.
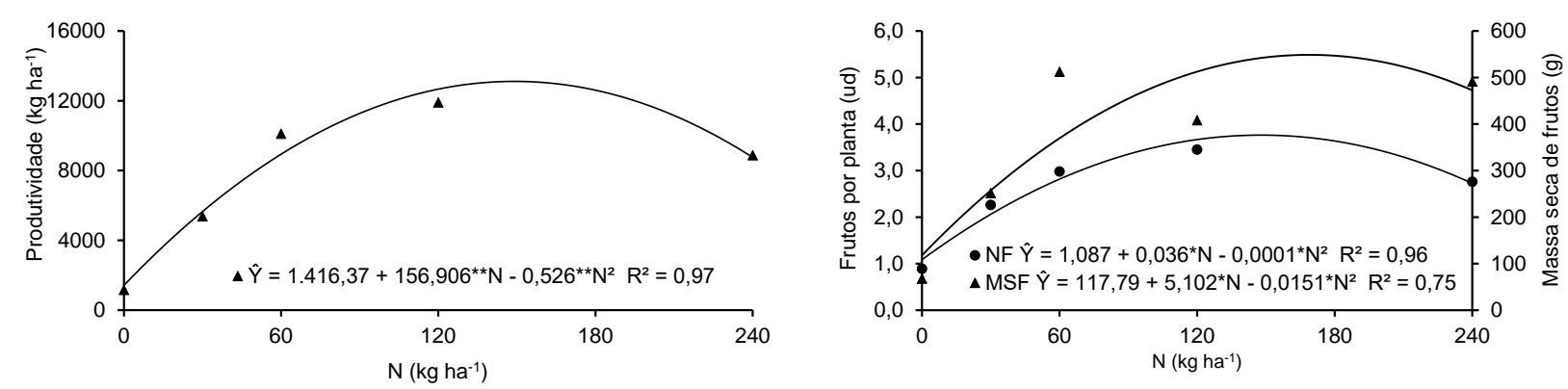

Figura 2 - A - Produtividade; B - número (NF) e massa sēca (MSF) de frutos de abóbora Tetsukabuto 'B8-A' em função de doses de nitrogênio (N) em NEOSSOLO QUARTZARÊNICO. 
Quanto à classificação dos frutos comercializáveis, frutos pequenos representaram maior proporção e tiveram a produtividade máxima estimada de $9.587 \mathrm{~kg} \mathrm{ha}^{-1}$ com a dose de $148 \mathrm{~kg} \mathrm{ha}^{-1}$ de $\mathrm{N}$ $\left(\hat{Y}=1.482,45+109,204^{*} \mathrm{~N}-0,367861^{*} \mathrm{~N}^{2} ; \mathrm{R}^{2}=0,9375\right)$; frutos médios tiveram a produtividade máxima estimada de $3.619 \mathrm{~kg} \mathrm{ha}^{-1}$ com a dose de $152 \mathrm{~kg} \mathrm{ha}^{-1}$ de N $\left(\hat{Y}=86,6235+46,445^{\star \star} N-0,152673^{* \star} N^{2} ; R^{2}=0,9833\right)$ enquanto para frutos grandes não houve resposta às doses de $\mathrm{N}$, sendo produzidos apenas $222 \mathrm{~kg} \mathrm{ha}^{-1}$ desses frutos com a dose de $60 \mathrm{~kg} \mathrm{ha}^{-1}$ de $\mathrm{N}$.

O número de frutos por planta foi crescente até a dose de $148 \mathrm{~kg} \mathrm{ha}^{-1}$ alcançando o máximo de 3,7 unidades. Na dose $0 \mathrm{~kg} \mathrm{ha}^{-1}$ de $\mathrm{N}$, foi estimado 1,1 e 2,7 unidades com $240 \mathrm{~kg} \mathrm{ha}^{-1}$ de N (Figura 2B). O número de frutos por planta apresentou elevada correlação $(r=0,9865 ; p=0,0009)$ com a produtividade de frutos comerciais. $\mathrm{O} N$ interferiu diretamente nos processos de crescimento e desenvolvimento das plantas (Figura 3). Assim, estes resultados demonstram o efeito da adubação nitrogenada na produção de abóbora híbrida Tetsukabuto, pela influência no incremento da massa fresca e no número de frutos por planta, o que também foi observado por Pedrosa et al. (2012) e Pôrto et al (2014).

O crescimento ótimo da moranga/abóbora híbrida é alcançado em solos de boa fertilidade, sendo relatados efeitos significativos do $\mathrm{N}$ e do fósforo (Puiatti e Silva, 2019). As plantas de abóbora híbrida Tetsukabuto, cv. B8-A, tiveram o seu crescimento influenciado pelas doses de N. O N, por fazer parte da molécula de clorofila, pode ter favorecido todo o aparato fotossintético e isso promoveu a produção de fotoassimilados, tendo em vista que o crescimento da planta é regulado por processos que otimizam a síntese de fotoassimilados (Engels et al., 2012).

Observou-se quatro fases de crescimento, definidas em função da quantidade acumulada de massa seca total da planta (Wt) e taxas de crescimento absoluto (Cwt), sendo que o tempo de duração dessas fases variou com as doses de $\mathrm{N}$ (Figuras $3 \mathrm{e} 4$ ).

$\mathrm{Na}$ Fase I, as plantas acumularam cerca de $10 \%$ da Wt final e apresentaram lento crescimento no período de 42 a 48 DAS. A dose de $120 \mathrm{~kg} \mathrm{ha}^{-1}$ de N proporcionou o maior Wt de $75,08 \mathrm{~g}_{\text {planta- }}^{-1} \mathrm{e}$ maior Cwt de 16,81 g planta- $^{-1}$ dia $^{-1}$, ao final da fase (Figura 3 e 4A). Houve influência do $N$ no crescimento das plantas pela diferença nos valores de $\mathrm{Wt}$ e Cwt em relação a dose $0 \mathrm{~kg} \mathrm{ha}^{-1}$ de $\mathrm{N}$, uma vez que, neste período, já havia sido aplicado $20 \%$ das doses de $\mathrm{N}$, aos 25 DAS. O crescimento lento na fase inicial é observado em diversas espécies vegetais pelo fato das plantas se apresentarem com menor volume de raiz, baixa absorção de água e de nutrientes, menor área foliar, além de reduzida taxa assimilatória líquida e taxa de respiração (Aumonde et al., 2011). Portanto, nesta fase, as folhas têm comportamento de fonte e dreno, pois armazenam os compostos advindos da própria produção de fotoassimilados (Lopes et al., 2011). Nas fases seguinte, o início do florescimento e frutificação faz com que os fotoassimilados sejam direcionados das folhas para os frutos de forma mais acelerada, pois são drenos preferenciais (Lopes et al., 2011), sendo as demais partes da planta (folhas, caules e raiz) usuários dos compostos provenientes do processo fotossintético em menor quantidade para a manutenção estrutural da planta.

A Fase II pode ser caracterizada como a fase de maior velocidade de crescimento, pois as plantas alcançaram a Cwt máxima com cerca de $50 \%$ da $W t$ final. O período de duração desta fase variou entre 10 e 14 dias, nos períodos de 42 a 60 DAS, conforme a dose de $\mathrm{N}$ aplicada, sendo o período mais curto para $30 \mathrm{~kg} \mathrm{ha}^{-1}$ e o mais longo para $240 \mathrm{~kg} \mathrm{ha}^{-1}$. A dose de $120 \mathrm{~kg} \mathrm{ha}^{-1}$, também, proporcionou a maior Wt de 412,19 $\mathrm{g} \mathrm{planta}^{-1}$ e a maior Cwt máxima de $33,81 \mathrm{~g} \mathrm{planta}^{-1} \mathrm{dia}^{-1}$, ao final da fase II (Figura 3 e 4A). Nesta fase, quando $60 \%$ das doses de $\mathrm{N}$ já haviam sido aplicadas, fica claro a influência do $\mathrm{N}$ no crescimento das plantas, pela grande diferença entre a Wt e Cwt no tratamento sem $\mathrm{N}$ e as demais doses de $\mathrm{N}$. E, também, observa-se 0 efeito negativo do $\mathrm{N}$ na maior dose de aplicada, pelos menores valores de Wt $\left(372,74 \mathrm{~g}\right.$ planta $\left.^{-1}\right)$ e Cwt $\left(24,39\right.$ g planta-1 $\left.^{-1} \mathrm{dia}^{-1}\right)$, quando comparada à dose de $120 \mathrm{~kg} \mathrm{ha}^{-1}$ de N (Figuras 3 e 4A).

As primeiras flores e frutos foram produzidas após os 45 DAS, ao final da Fase II, verificando o início da fase reprodutiva. Nessa fase, observou-se a translocação de fotoassimilados para as flores e frutos, que acumularam massa seca (Wfr) de modo diferenciado em função do $\mathrm{N}$ aplicado, pois foram estimados valores iguais a 12,02; 79,36; 182,77; 139,83 e 157,72 g planta- $^{-1}$, para $0,30,60,120$ e $240 \mathrm{~kg} \mathrm{ha}^{-1}$ de $\mathrm{N}$, respectivamente (Figura 3). Logo, a força de drenos da planta foi alterada pela predominância da fase reprodutiva sobre a vegetativa, aumentando a translocação de fotoassimilados das folhas para os frutos (Marschner, 2012). O N influenciou a força dos drenos principais, flores e fruto, pelo incremento na aceleração da Cwfr, principalmente, na dose de $120 \mathrm{~kg} \mathrm{ha}^{-1}$, nessa Fase II (Figura 4B).

A desaceleração no crescimento das plantas e o alcance de $100 \%$ da Wt, associado à maturação dos frutos, caracterizam a Fase III. O período de duração desta fase variou entre 19 e 28 dias, no período de 71 a 87 DAS, conforme a dose de $\mathrm{N}$ aplicada, também, com o período mais curto para $30 \mathrm{~kg} \mathrm{ha}^{-1} \mathrm{e}$ o mais longo para $240 \mathrm{~kg} \mathrm{ha}^{-1}$. Nessa fase, as plantas continuaram acumulando massa seca, porém com Cwt cada dia menor até atingir $100 \%$ de Wt da planta. Com $30 \mathrm{~kg} \mathrm{ha}^{-1}$, as plantas de abóbora atingiram mais cedo (71 DAS) a Wt máxima da planta de 420,59 $\mathrm{g}_{\text {planta }}{ }^{-1}$, enquanto as plantas com $240 \mathrm{~kg} \mathrm{ha}^{-1}$ foram mais tardias (87 DAS) com Wt máxima de $735,88 \mathrm{~g} \mathrm{planta}^{-1}$. Ao final desta Fase III, a dose de $120 \mathrm{~kg} \mathrm{ha}^{-1}$ proporcionou a maior Wt máxima de 799,00 $\mathrm{g}_{\text {planta-1}}{ }^{-1}$, aos 77 DAS (Figuras $3 \mathrm{e}$ 4). 


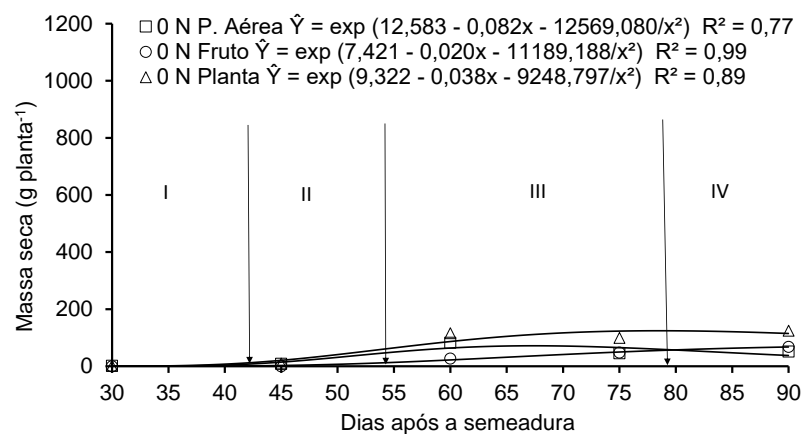

C
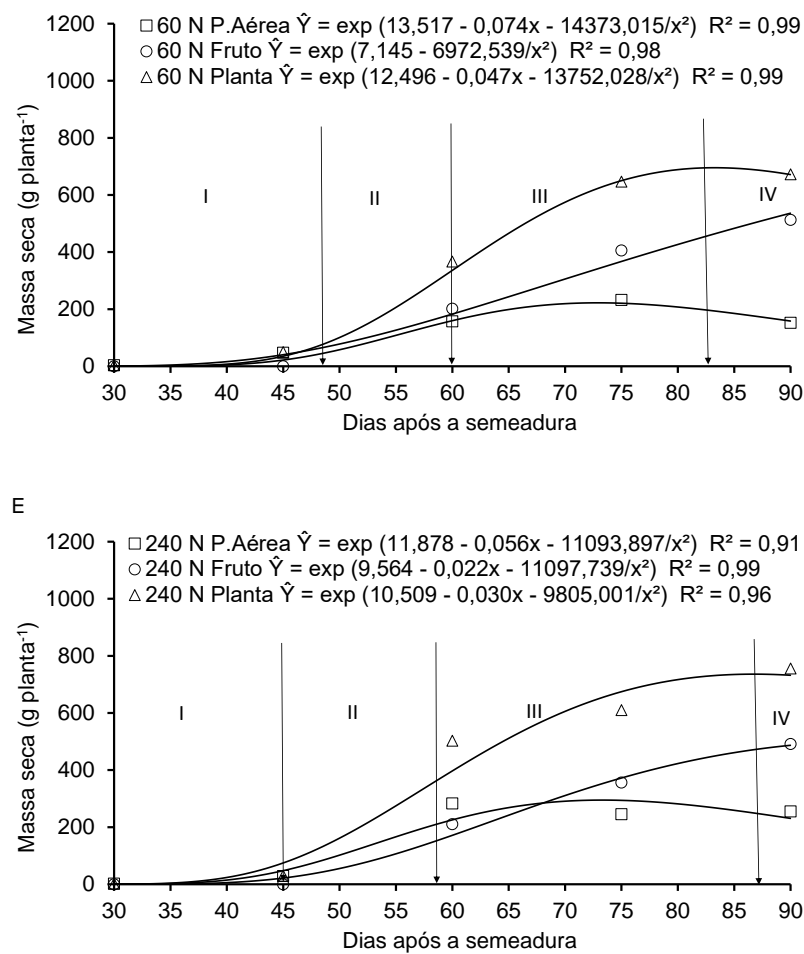

B
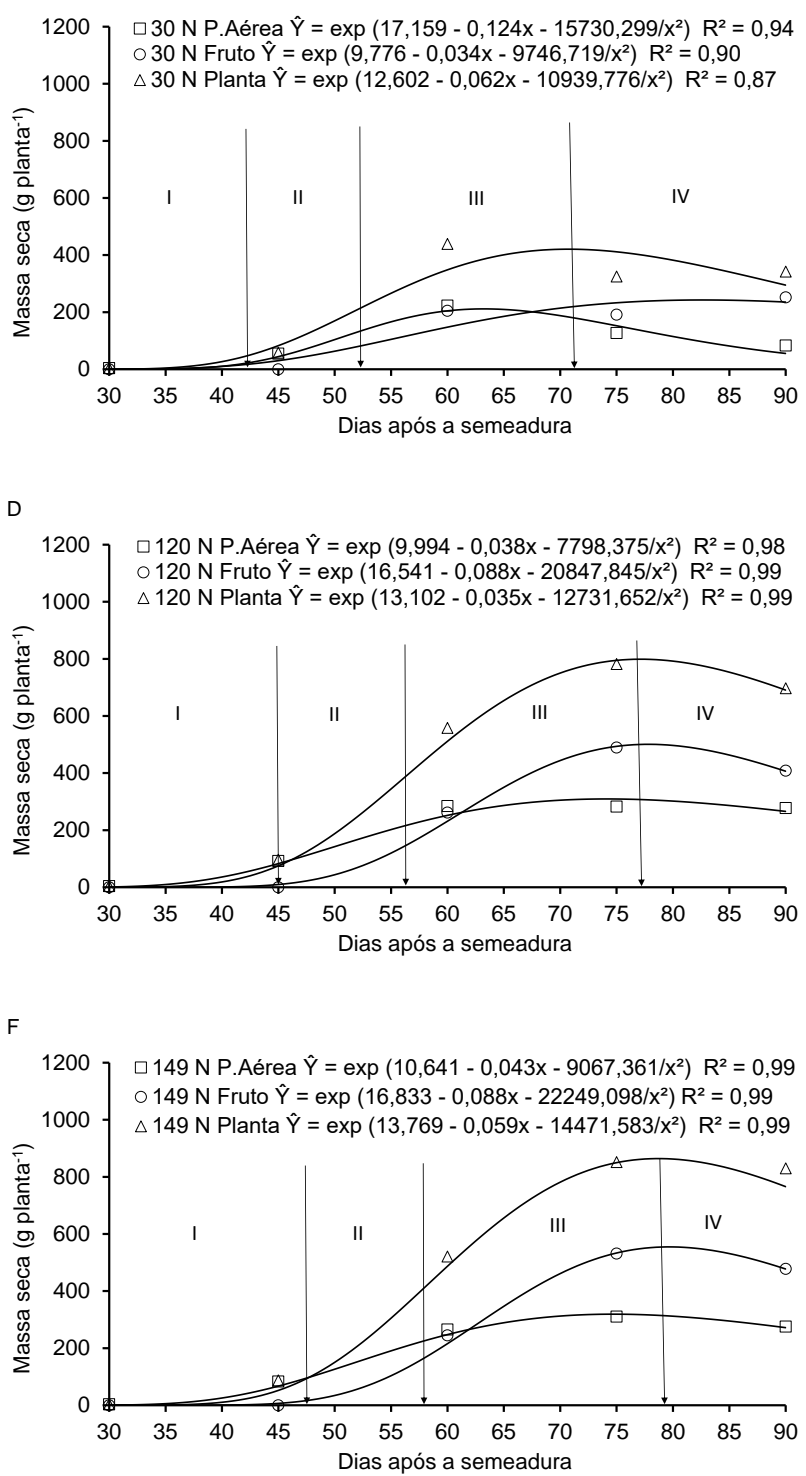

Figura 3 - Massa seca total de planta $(W t)$, da parte aérea e de frutos de abóbora Tetsukabuto 'B8-A' para as doses de nitrogênio: 0 (A), 30 (B), 60 (C), 120 (D), 240 (E) e $149 \mathrm{~kg} \mathrm{ha}^{-1}$ de N (F), em NEOSSOLO QUARTZARÊNICO, em função da idade das plantas, nas fases de crescimento I, II, III e IV.

A

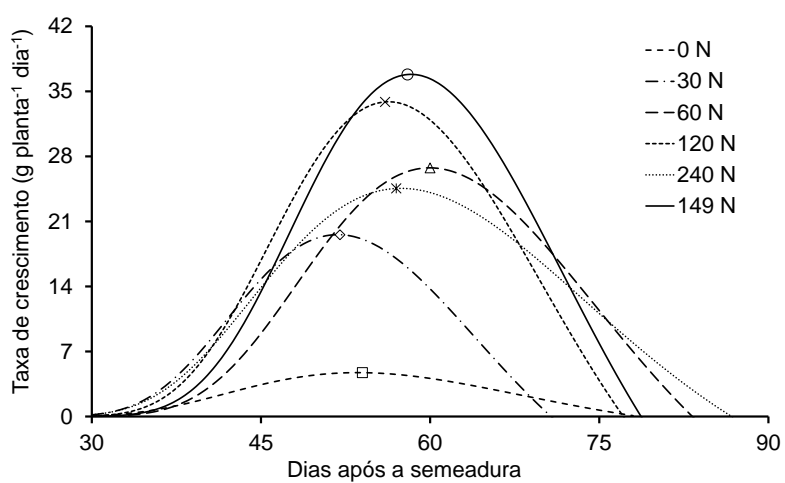

B

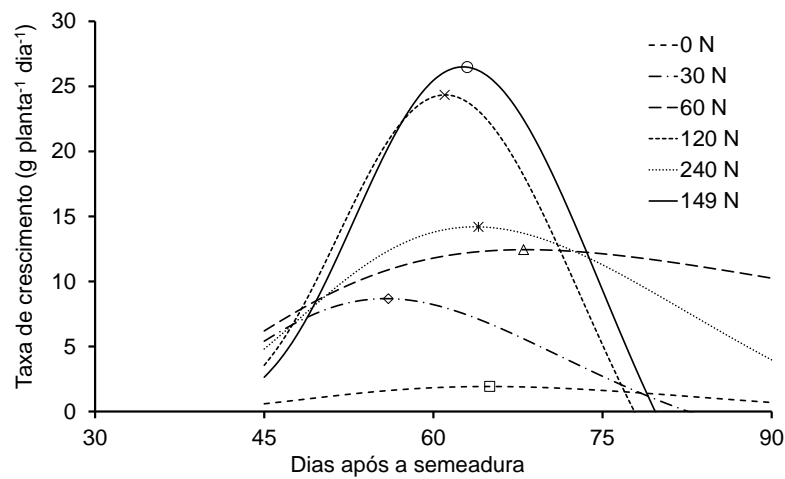

Figura 4 - Taxa de crescimento absoluto da planta - Cwt (A) e taxa de crescimento absoluto de frutos - Cwfr (B) de plantas de abóbora Tetsukabuto 'B8-A' em função de doses de nitrogênio (N), em NEOSSOLO QUARTZARÊNICO. 
Durante a Fase III, no período de 63 a 74 DAS, ocorreu o acúmulo máximo de massa seca da parte aérea (Wpa) em todos as doses. $E$, com $120 \mathrm{~kg} \mathrm{ha}^{-1} \mathrm{de}$ $\mathrm{N}$, foi estimado o maior Wpa de $309,12 \mathrm{~g}$ planta $^{-1}$ (Figura 3). Além disso, os frutos atingiram a Cwfr máxima nesta fase para todas as doses de $\mathrm{N}$. Aos 61 DAS, a dose de $120 \mathrm{~kg} \mathrm{ha}^{-1}$ proporcionou a maior Cwfr máxima, 24,34 $\mathrm{g}_{\text {planta- }} \mathrm{dia}^{-1}$, valor muito superior às Cwfr máximas nas demais doses de $\mathrm{N}$ (Figura 4B). Nesta fase, a diminuição do crescimento se deve a continuada mudança de relação fonte/dreno iniciada ao final da Fase II, pois o $\mathrm{N}$ atua diretamente nas relações fonte/dreno, por alterar a distribuição de assimilados entre a parte vegetativa e reprodutiva (Queiroga et al., 2007).

A

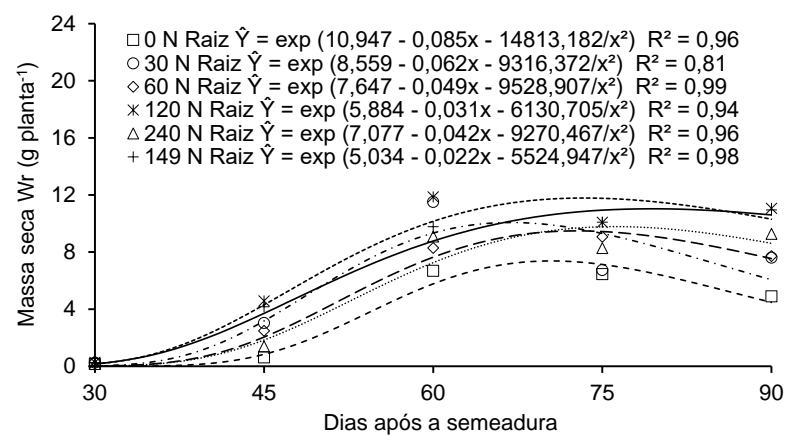

O acúmulo máximo de massa seca nas raízes (Wr) foi observado nessa Fase III no período entre 67 e 76 DAS. Com $120 \mathrm{~kg} \mathrm{ha}^{-1}$ de N, foi estimado o maior $\mathrm{Wr}$ $\left(11,78 \mathrm{~g} \mathrm{planta}^{-1}\right)$ e o menor (7,37 $\left.\mathrm{g}_{\text {planta-1 }}^{-1}\right)$, com $0 \mathrm{~kg} \mathrm{ha}^{-1}$ de N. No entanto, as raízes atingiram a Cwr máxima entre 47 e 54 DAS, com as menores Cwr máxima estimadas com a dose 0 e $120 \mathrm{~kg} \mathrm{ha}^{-1}$, iguais a 0,38 e 0,39 g planta $^{-1}$ dia $^{-1}$, respectivamente (Figura 5).

A definição da produção de abóbora é na Fase III, que é a fase de crescimento mais importante para a adubação, época em que as plantas necessitam da maior disponibilidade de N, como observado por Vidigal et al. (2007), em que as plantas de abóbora híbrida Tetsukabuto absorvem a maior de parte do $\mathrm{N}$, cerca de $78 \%$, no período de 49 a 77 DAS.

B

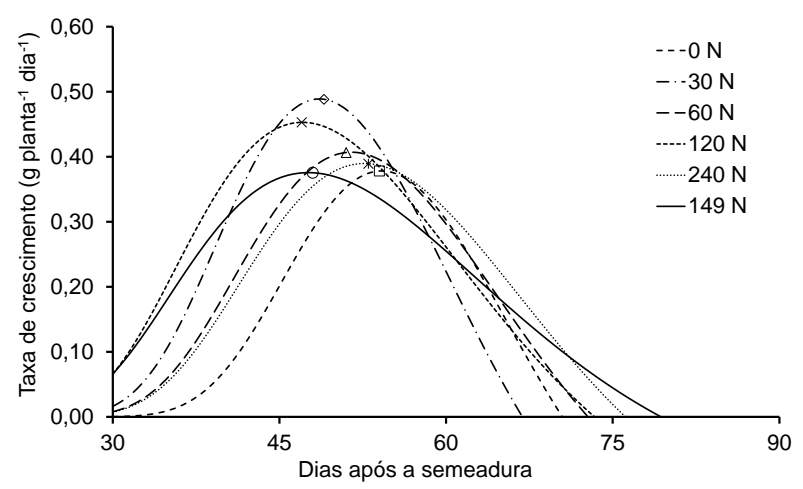

Figura 5 - Massa seca total de raiz - $\operatorname{Wr}(\mathrm{A})$ e taxa de crescimento absoluto de raiz - Cwr (B) de plantas de abóbora Tetsukabuto 'B8-A' para as doses de nitrogênio: 0, 30, 60, 120, 149 e $240 \mathrm{~kg} \mathrm{ha}^{-1}$ de N, em NEOSSOLO QUARTZARÊNICO.

A Fase IV foi caraterizada pela redução da Wt e valores negativos de Cwt. Isto se deveu, provavelmente, à perda de massa seca de parte aérea (ramos e folhas senescentes) até a colheita dos frutos, que ocorreu aos 90 DAS, finalizando o ciclo da abóbora em todos os tratamentos, pois os frutos apresentavam-se no ponto de colheita. Logo, a Fase IV teve o tempo de duração mais curto, sendo de 11, 19, 7, 13 e 3 dias para as doses $0,30,60,120$ e $240 \mathrm{~kg} \mathrm{ha}^{-1}$ de $\mathrm{N}$, respectivamente. Na maior dose de $\mathrm{N}$ aplicada, as plantas continuaram a crescer até próximo à colheita dos frutos. $\mathrm{O}$ excesso de $\mathrm{N}$ pode promover o crescimento vegetativo supranormal com o desfavorecimento ao início do estádio reprodutivo, além de menor número e tamanho do produto comercial das hortaliças (Vidigal et al., 2019).

Apesar de a Wt máxima das plantas ter marcado o final da Fase III, foi na Fase IV que os frutos alcançaram o máximo acúmulo de massa seca, estimados aos $90,83,90,78$ e 90 DAS, as massas secas de 67,$39 ; 242,84 ; 536,05 ; 500,59$ e 486,79 g planta $^{-1}$ para as doses $0,30,60,120$ e $240 \mathrm{~kg} \mathrm{ha}^{-1}$ de N, respectivamente (Figura 3). Portanto, o $\mathrm{N}$ teve influência direta no período de crescimento e desenvolvimento das plantas de abóbora híbrida Tetsukabuto. A menor disponibilidade de $\mathrm{N}$ pode limitar o tempo para as plantas atingirem o máximo acúmulo de massa seca, enquanto a maior disponibilidade de $\mathrm{N}$ pode permitir que as plantas tenham mais tempo para atingirem esse máximo acúmulo de massa seca.

A dose $149 \mathrm{~kg} \mathrm{ha}^{-1}$ de $\mathrm{N}$ proporcionou a máxima produtividade de frutos comerciais (Figura 2A), logo é a dose ótima para a produção de abóbora híbrida Tetsukabuto nas condições deste trabalho. Esse fato é confirmado pela otimização do crescimento e do desenvolvimento das plantas, pois essa dose de $\mathrm{N}$ proporcionou os maiores valores estimados de $\mathrm{Wt}$ $\left(864,07 \mathrm{~g}\right.$ planta- $\left.^{-1}\right)$, Wpa $\left(318,90 \mathrm{~g}\right.$ planta $\left.^{-1}\right)$, Wfr (554,55 $\mathrm{g}$ planta $\left.^{-1}\right)$, além de Cwt $\left(36,81 \mathrm{~g} \mathrm{planta}^{-1} \mathrm{dia}^{-1}\right)$ e Cwfr (26,48 g planta-1 dia-1 $^{-1}$ (Figuras 3F e 4). Esse resultado pode ser explicado pela afirmação de Queiroga et al. (2007) de que plantas com maiores massa e área foliar têm maior produção de fotoassimilados e de frutos. O maior acúmulo de massa seca na dose de $149 \mathrm{~kg} \mathrm{ha}^{-1}$ relaciona-se ao aumento na taxa fotossintética e na produção de fotoassimilados e de outros compostos estruturais, como aminoácidos, carboidratos e gorduras (Lima et al., 2011; Tuncay et 
al., 2011), resultando em maior massa de órgãos reprodutivos, como flores e frutos. A máxima produtividade de abóbora Tetsukabuto foram estimadas com $300 \mathrm{~kg} \mathrm{ha}^{-1}$ (Pedrosa et al., 2012), $260 \mathrm{~kg} \mathrm{ha}^{-1}$ (Pôrto et al., 2014), $146 \mathrm{~kg} \mathrm{ha}^{-1}$ de $\mathrm{N}$ (Marouelli et al., 2017) e neste trabalho $149 \mathrm{~kg} \mathrm{ha}{ }^{-1}$ de $\mathrm{N}$, todas superior a $80 \mathrm{~kg} \mathrm{ha}^{-1}$, a dose recomendada por Vidigal et al (2017). Isto sugere que o potencial produtivo da abóbora Tetsukabuto pode ser ampliado com o uso de maiores doses de $\mathrm{N}$.

A influência do $\mathrm{N}$ na partição de fotoassimilados foi observada pela quantidade máxima de massa seca nas diferentes partes da planta de abóbora híbrida Tetsukabuto, variando com as doses ao longo do ciclo (Figura 6). O acúmulo de massa seca na raiz e na parte aérea manteve-se equilibrada em todas as doses de $\mathrm{N}$, no período entre 30 e 45 DAS, quando a parte aérea acumulou cerca de 90 a 95\% da massa seca da planta, isto pode ser pelo crescimento lento das plantas, observado na Fase I (Figura 3). A partir dos 45 DAS, na Fase II, observa-se redução no acúmulo de massa seca nas raízes com as doses de $\mathrm{N}$ e maior acúmulo na parte aérea e frutos até o final do ciclo (Figuras 3 e 6). Nas Fases III e IV, o N promove maior acúmulo de massa seca nos frutos pela mudança na relação fonte/dreno, com a entrada da fase reprodutiva, as flores e frutos das plantas de abóbora tornam-se os drenos preferenciais (Lopes et al., 2011).

$\mathrm{Na}$ dose de $240 \mathrm{~kg} \mathrm{ha-1}$, observaram-se 2,7 frutos planta $^{-1}$, menor número de drenos preferenciais que os 3,7 frutos planta-1 estimado com $149 \mathrm{~kg} \mathrm{ha}^{-1}$ de $\mathrm{N}$ (Figura 2B). Logo, a maior quantidade de $\mathrm{N}$ disponível pode ter sido responsável pelo menor crescimento das plantas por interferência negativa na fase reprodutiva das plantas de abóbora híbrida Tetsukabuto, seja por promover o crescimento vegetativo supranormal com o desfavorecimento ao início do estádio reprodutivo, como efeito do excesso de $\mathrm{N}$ (Vidigal et al., 2019). Por outro lado, o número de frutos por planta apresentou correlação positiva $(r=0,9752$; $p=0,023$ ) com a massa seca de frutos, que aumentou até a dose de $169 \mathrm{~kg} \mathrm{ha}^{-1}$ (Figura 2B) com o $\mathrm{N}$ aplicado. A competição por fotoassimilados entre drenos e entre dreno e fonte afeta a taxa de crescimento da planta e a fixação dos frutos. Ou seja, o aumento no número de frutos na planta pode aumentar a quantidade de fotoassimilados alocados nos frutos às expensas do crescimento das partes vegetativas (Andriolo e Falcão, 2000).

No final do ciclo, os frutos acumularam mais massa seca 54,5\%; 73,5\%; 76,2\%; 58,6\% e 65,0\% da Wt, com as doses 0, 30, 60, 120 e $240 \mathrm{~kg} \mathrm{ha}^{-1}$ de $\mathrm{N}$, respectivamente. Para a dose de $149 \mathrm{~kg} \mathrm{ha}^{-1}$ de $\mathrm{N}$, o acúmulo de massa seca nos frutos foi de $62,5 \%$ (Figuras 3 e 6), demonstrando ser o dreno principal na par- tição de fotoassimilados, como observado por Vidigal et al. (2007), a exemplo do ocorrido com melão (Queiroga et al., 2008), melancia (Vidigal et al., 2009; Almeida et al., 2012), pimenta (Pedó et al., 2013) e tomate (Martinazzo et al., 2015).

$\mathrm{O}$ acúmulo máximo de massa seca $(\mathrm{Wt})$ ocorreu antes da colheita dos frutos, finalizando o ciclo das plantas de abóboras. O fato é que na fase final do ciclo, com a maturação dos frutos, a parte aérea (ramos e folhas) entra em senescência com perda de parte da massa seca acumulada, porém, ocorrendo ainda alguma translocação de fotoassimilados e nutrientes para os frutos, drenos preferenciais (Lopes et al., 2011), que tiveram o máximo acúmulo de massa seca mais próximo da colheita ou mesmo na colheita (Figuras 3 e 6).

Maior disponibilidade de nutrientes, na época de maior absorção, é um dos fatores que promovem o crescimento das plantas e permite que essas expressem o seu potencial de crescimento e produção. O N é o segundo nutriente mais absorvido pela abóbora híbrida Tetsukabuto (Vidigal et al., 2007), destacandose pela quantidade exigida e pelas funções que exerce na planta. Como parte da molécula de clorofila, o N favorece o aparato fotossintético e promove a otimização da produção de fotoassimilados (Engels et al., 2012). Logo, o manejo da adubação nitrogenada merece atenção para a garantia de produtividade e qualidade dos frutos de abóbora híbrida Tetsukabuto, bem como de outras hortaliças.

O aumento na produtividade de frutos em função da adubação nitrogenada em cobertura ocorreu pelo aumento da produção de massa seca da planta, uma vez que o acúmulo máximo de massa seca na parte aérea, frutos e raízes e, consequentemente, na planta inteira (Wt) foi superior em todas as doses de $\mathrm{N}$ aplicadas em relação ao tratamento sem aplicação de $\mathrm{N}$. Além disso, também se observou maiores taxas de crescimento absoluto $(\mathrm{Cw})$ quando se aplicou $\mathrm{N}$.

\section{Conclusões}

O crescimento da abóbora híbrida Tetsukabuto 'B8-A' é influenciado por doses nitrogênio aplicado em cobertura.

O nitrogênio altera a partição de fotoassimilados entre os órgãos da planta de abóbora híbrida Tetsukabuto.

A aplicação de $\mathrm{N}$ em cobertura aumenta a produtividade de frutos comercializáveis de abóbora híbrida Tetsukabuto 'B8-A' até $149 \mathrm{~kg} \mathrm{ha}^{-1}$ de N.

\section{Agradecimentos}

À Fundação de Amparo à Pesquisa do Estado de Minas Gerais (FAPEMIG) pelo auxílio financeiro. 
A

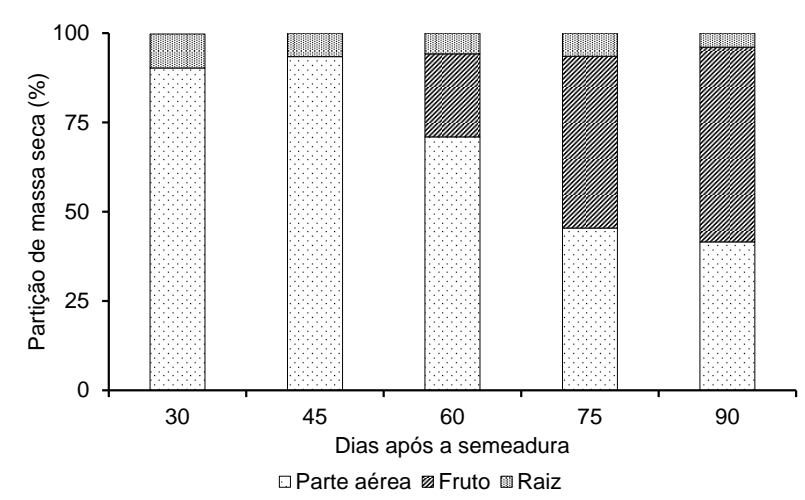

C

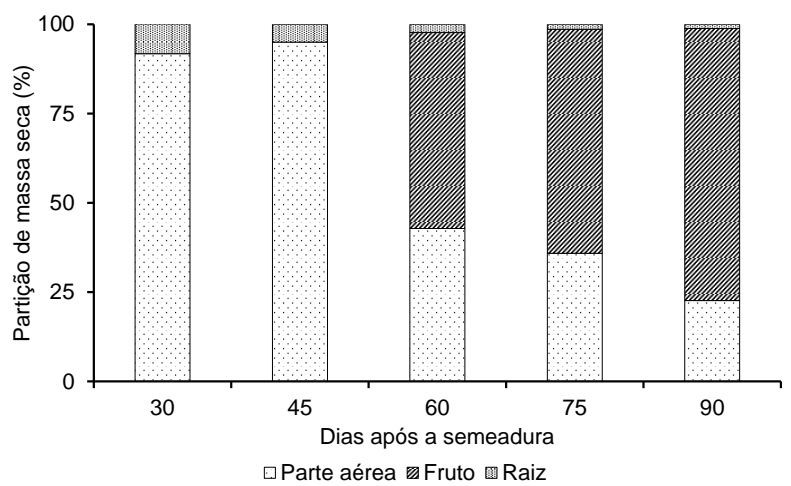

E

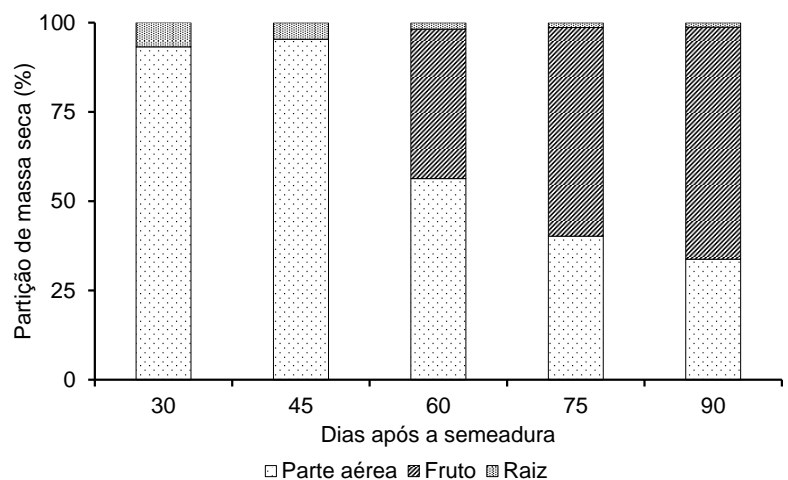

B

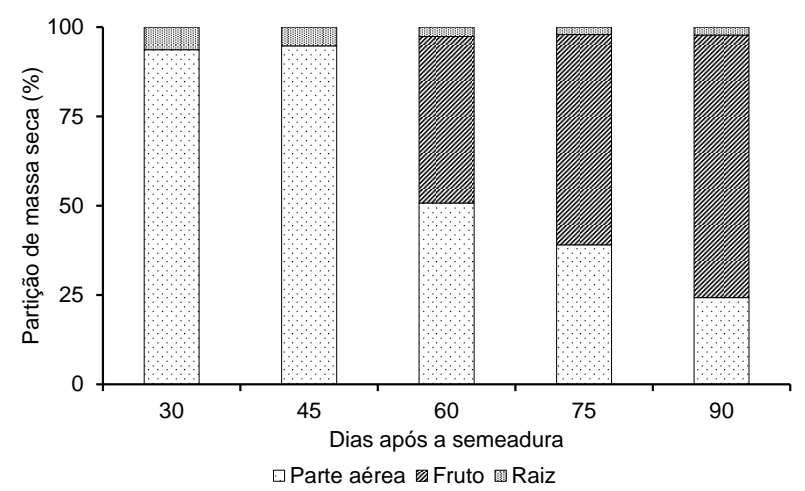

D

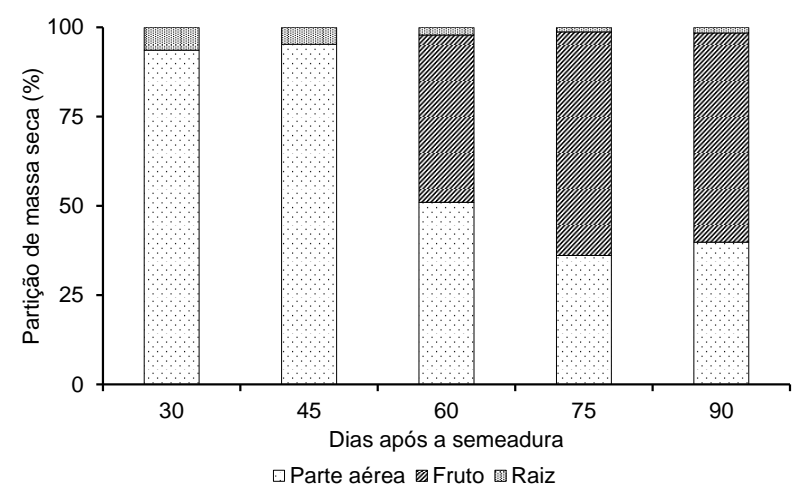

$\mathrm{F}$

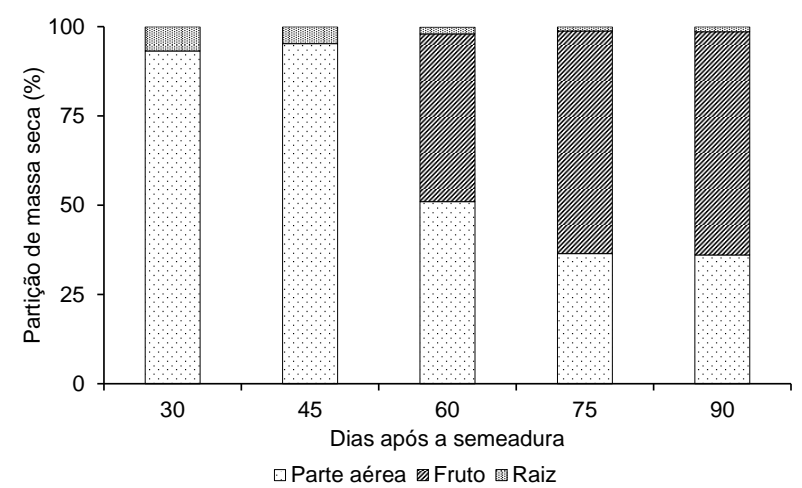

Figura 6 - Partição de fotoassimilados na planta de abóbora Tetsukabuto 'B8-A' em função de doses de nitrogênio: 0 (A), 30 (B), 60 (C), 120 (D), 240 (E) e $149 \mathrm{~kg} \mathrm{ha}^{-1}$ de N (F), em NEOSSOLO QUARTZARÉNICO.

\section{Referências}

Almeida EIB, Corrêa MCM, Nobrega GN, Pinheiro EAR, Lima FF (2012) Crescimento e marcha de absorção e macronutrientes para a cultivar de melancia Crimson Sweet. Revista Agro@mbiente On-line 6 (3):205-214.

Andriolo JL, Falcão LL (2000) Efeito da poda de folhas sobre a acumulação de matéria seca e sua repartição para os frutos do tomateiro cultivado em ambiente protegido. Revista Brasileira de Agrometeorologia, 8: 75-83.

Aumonde TZ, Lopes NF, Moraes DM, Peil RMN, Pedó T (2011) Análise de crescimento do híbrido de mini melancia Smile $\AA$ enxertada e não enxertada. Interciência 36(9):677-681.
Cecílio Filho AB, Carmona VMV, Schiavon Junior AA (2017) Broccoli growth and nutrient accumulation. Científica 45(1):95-104.

Cruz, CD (2013) Genes: a software package for analysis in experimental statistics and quantitative genetics. Acta Scientiarum. Agronomy 35(3):271-276.

Damasceno APB, Medeiros JF, Medeiros DC, Melo IGC, Dantas DC (2012) Crescimento e marcha de absorção de nutrientes do melão cantaloupe tipo "Harper" fertirrigado com doses de $\mathrm{N}$ e K. Revista Caatinga 25(1):137-146.

Engels C, Kirkby E, White P (2012) Mineral nutrition, yield and source-sink relationships. In: Marschner $\mathrm{H}$ (ed). Mineral nutrition of higher plants. 3ed. San Diego: Academic Press. p.85-133. 
Lima MC, Amarante L, Mariot M, Serpa R (2011) Crescimento e produção de pigmentos fotossintéticos em Achillea millefolium L. cultivada sob diferentes níveis de sombreamento e doses de nitrogênio. Ciência Rural 41(1):45-50.

Lopes WAR, Negreiros MZ, Dombroski JLD, Rodrigues GSO, Soares AM, Araújo AP (2011) Análise do crescimento de tomate 'SM-16' cultivado sob diferentes coberturas de solo. Horticultura Brasileira 29(4): 554-561.

Marouelli WA, Amaro GB, Braga MB (2017) Response of hybrid squash Tetsukabuto to water depths and doses of nitrogen. Horticultura Brasileira 35(3):402-409.

Marschner H (2012) Mineral nutrition of higher plants. 3.ed. San Diego: Academic Press. 643p.

Martinazzo EG, Perboni AT, Posso DA, Aumonde TZ, Bacarin MA (2015) Análise de crescimento e partição de assimilados em plantas de tomateiro cv. Micro-Tom submetidas ao nitrogênio e piraclostrobina. Semina: Ciências Agrárias 36(5):3001-3012.

Nick C, Borém A (2017) Abóboras e Morangas: do plantio à colheita. Viçosa: UFV. 203p.

Pedó T, Aumonde TZ, Lopes NF, Villela FA, Mauch CR (2013) Análise comparativa de crescimento entre genótipos de pimenta cultivados em casa de vegetação. Biosciense Journal 29(1):125-131.

Pedrosa MW, Mascarenhas MHT, Freire FM, Viana MCM, Gonçalvez LD, Lara JFR, Ferreira PC (2012) Produção e qualidade da moranga híbrida em resposta a doses de nitrogênio. Horticultura Brasileira 30(2): 355--358.

Pôrto MLA, Puiatti M, Fontes PCR, Cecon PR, Alves JC (2014) Produtividade e acúmulo de nitrato nos frutos da abóbora "Tetsukabuto" em função da adubação nitrogenada. Horticultura Brasileira 32(3):280-285.

Puiatti M, Silva DJH (2019) Abóboras e morangas. In Fontes PCR (Ed.) Olericultura - teoria e prática. 2ed. Viçosa: UFV, p. 363-384.
Queiroga RCF, Puiatti M, Fontes PCR, Cecon PR, Finger FL (2007) Influência de doses de nitrogênio na produtividade e qualidade do melão Cantalupensis sob ambiente protegido. Horticultura Brasileira 25(4): 550-556.

Queiroga RCF, Puiatti M, Fontes PCR, Cecon PR (2008) Partição de assimilados e índices fisiológicos de cultivares de melão do grupo Cantalupensis influenciados por número e posição de frutos na planta, em ambiente protegido. Revista Ceres 55(6):595-604.

Tuncay Ö, Eșilyok D, Yağmur B, Okur B (2011) Yield and quality of garden cress affected by different nitrogen sources and growing period. African Journal of Agricultural Research, 6(3):608-617.

Vidigal SM. Pacheco DD, Facion CE (2007) Crescimento e acúmulo de nutrientes pela abóbora híbrida Tetsukabuto. Horticultura Brasileira 25(3):375-380.

Vidigal SM, Pacheco DD, Costa EL, Facion CE (2009) Crescimento e acúmulo de macro e micronutrientes pela melancia em solo arenoso. Revista Ceres 56(1):112-118.

Vidigal SM, Moreira MA, Pereira PRG (2010) Crescimento e absorção de nutrientes pela planta cebola cultivada no verão por semeadura direta e por transplantio de mudas. Bioscience Journal 26(1):59-70.

Vidigal SM, Puiatti M, Sediyama MAN (2017) Correção do solo e adubação. In: Nick C, Borém A (Eds.) Abóboras e Morangas: do plantio à colheita. Viçosa: UFV. p. 49-69.

Vidigal SM, Cecílio Filho AB, Cortez JWM, Pereira PRG (2019) Diagnóstico visual na avaliação do estado nutricional das hortaliças. Informe Agropecuário 40(308):41-54. 